\title{
Automatização do Controle de Fluxo dos Livros de uma Biblioteca Universitária
}

\author{
Ivanicio B. S. Junior, José Wenzel Trieste Ribeiro, Felipe Francisco Bezerra \\ Araújo
}

Instituto de Educação Superior Raimundo Sá (IESRSA) - Picos, PI - Brasil

Departamento de Ciência da Computação

ivaniciojr@gmail.com, wenzel_contato@hotmail.com, felipefba@hotmail.com

\begin{abstract}
This paper describes how the use of RFID technologies and automation processes with Arduino was measured to optimize the control and workflow of a university library. The goal of the project is to verify the feasibility of this technology to control the flow of books in a university library. For this, we interviewed the supervisor of a library and used his answers to define the system requirements. It will be implemented as a middleware in order to provide support for the existing system.
\end{abstract}

Resumo: $O$ presente trabalho descreve como foi mensurada a utilização das tecnologias RFID e de processos de automatização com Arduino, para otimizar o controle e fluxo de trabalho de uma biblioteca universitária. O objetivo deste projeto é verificar a viabilidade desta tecnologia no controle de fluxo de livros em uma biblioteca universitária. Para isto, foi feita uma entrevista com o supervisor geral de uma biblioteca, cujas respostas serviram de base para determinar os requisitos do sistema. Este será implementado no formato de middleware, de modo a dar apoio ao sistema já existente.

\section{Introdução}

A tecnologia RFID (do inglês Radio Frequency Identification, Identificação por Radiofrequência) é uma tecnologia para identificação de transmissores através de sinais de rádio. Ela serve como alternativa a outros métodos de identificação, como o código de barras, possibilitando o controle de fluxo e monitoramento de produtos de forma eficiente. A vantagem da RFID é que ela permite identificar objetos mesmo que o transmissor não esteja visível.

Esta tecnologia está associada a implantação de leitores e transmissores que irão emitir sinais e captá-los. O leitor transmite ondas de rádio, que são captadas pelos transmissores e geram energia para os mesmos. Com isto, os transmissores conseguem gravar os dados recebidos e enviar uma resposta ao leitor. Existem vários tipos de leitores e transmissores de tamanhos e capacidades variados, que devem ser utilizados de maneira mais apropriada para sua finalidade. Alguns transmissores possuem capacidade de armazenamento facilitando seu uso para determinada situação, como por exemplo no gerenciamento de empréstimos de uma biblioteca, em que o próprio transmissor pode armazenar informações sobre o empréstimo e situação do exemplar.

Neste trabalho verificamos a possibilidade de implementação de um sistema utilizando as tecnologias RFID e Arduino na biblioteca José Antenor de Castro Neiva Júnior, do campus do Instituto de Educação Superior Raimundo Sá (IESRSA). O restante deste artigo está dividido da seguinte forma. Na Seção 2 apresentamos uma breve revisão bibliográfica sobre o tema. Na Seção 3 descrevemos as principais características do 
ambiente em que o sistema será implantado com base em uma entrevista com o bibliotecário e supervisor da biblioteca. Na Seção 4 apresentamos os requisitos do sistema, elaborados de acordo com os dados das seções anteriores. Por fim, a Seção 5 encerra o artigo, apresentando conclusões e propondo trabalhos futuros.

\section{Revisão bibliográfica}

A tecnologia RFID foi aprimorada ao longo dos anos de modo a se tornar acessível para seu uso e ser disseminado de forma confiável. Através do seu crescimento gradativo esta tecnologia passou-se a ser uma excelente opção, na qual sua implementação é bastante eficiente, em que consequentemente o levou a ser um possível substituto do código de barras. Ainda é necessário ser realizado um trabalho considerável para que a tecnologia RFID seja difundida tanto quanto a do código de barras, embora ela esteja sendo rapidamente implementada, conforme Roberts (2006).

A RFID tem um bom custo benefício, visto que o mesmo equipamento pode ser reutilizado várias vezes para armazenar dados diferentes, além de ser de fácil implementação como melhoria para o desenvolvimento acadêmico. O emprego desta tecnologia é comumente utilizado em acervos bibliotecários de modo a automatizar a efetivação de empréstimos, mostrando avanço significativo na finalidade acadêmica. De acordo com França Neto (2008), o uso de códigos de barras consome muito tempo e resulta em custos adicionais, além de requerer que as etiquetas estejam alinhadas com o leitor. Estes problemas podem ser contornados pela implementação da tecnologia RFID.

A utilização do sistema RFID tende a ser um sistema abrangente no qual atende todas as necessidades de segurança e rastreamento de materiais de uma biblioteca, de acordo com Sahid (2005). A aplicação de leitores para a emissão dos sinais auxilia no desenvolvimento de sistemas antifurto, no qual é de suma importância para garantir a confiabilidade e segurança em bibliotecas em que será verificado se a obra está ou não emprestado.

O modo utilizado para gerir o processo de empréstimo na biblioteca é fixando transmissores adesivos pouco perceptíveis em exemplares das obras que irão gravar dados no transmissores assim podendo agilizar e garantir o empréstimo. Através dos leitores será feita a identificação se o exemplar está ou não emprestado assim garantido a confiabilidade do sistema antifurto que irá detectar qualquer alteração feita nos dados do transmissor.

A implementação de uma nova tecnologia não é somente para praticidade e eficiência em determinada situação, mas também para ter um retorno no investimento que foi gasto. Coyle (2005) menciona que todo um investimento em uma nova tecnologia que irá ser aplicada, terá seu custo equiparado ao aumento dos seus lucros, e caso seus lucros aumentem serão suficientes para pagar a nova tecnologia empregada.

\section{Entrevista com o bibliotecário}

Conforme dito anteriormente, este trabalho visa verificar a viabilidade de um sistema utilizando as tecnologias RFID e Arduino na biblioteca José Antenor de Castro Neiva Júnior, do campus do Instituto de Educação Superior Raimundo Sá (IESRSA). Para isto, foi realizada uma entrevista com o bibliotecário e supervisor geral, José de Sousa, de modo a compreender e extrair informações de como o sistema já implantado funciona, quais são as dificuldades enfrentadas no dia a dia do campus e como esta nova tecnologia pode tornar o processo de aquisição, manutenção, empréstimo e devolução dos livros mais conveniente para os alunos e para a Instituição.

O sistema implantado na biblioteca da IESRSA é o Biblios, no qual visa administrar várias funções requeridas no dia a dia de uma biblioteca, como gerenciamento 
do acervo bibliográfico, entrada e saída de livros, geração de relatórios com os mais variados filtros, gerenciamento de fluxo de caixa apurado com o dinheiro das multas de atraso e etc. No que se faz de base a um sistema com regras de negócio de uma biblioteca, o Biblios consegue adequar e conciliar-se muito bem às tarefas do dia a dia em uma biblioteca universitária.

Apesar do sistema oferecer diversos recursos técnicos, ainda se faz necessária bastante operação manual para a realização de funções simples, como por exemplo a digitação do código de barras do item do acervo no momento do empréstimo do exemplar. Este processo manual torna o fluxo de empréstimos inconveniente para os profissionais e alunos. Em um dia com um fluxo elevado de pessoas, a dificuldade de gerenciar e controlar a saída de livros, bem como a conservação dos mesmos, é complicada e improdutiva, podendo gerar resultados inesperados para a Instituição, para os alunos e para os professores, que consomem os itens do acervo diariamente. Acontecimentos como furtos ou danos aos exemplares, que trazem prejuízos à Instituição, são relativamente raros. Uma situação frequente citada por José de Sousa foi que, em horários de fluxo elevado de pessoas, não haver certeza se o(s) aluno(s) já realizaram o empréstimo do exemplar nas suas mãos. Esse tipo de questionamento varia em situações que há uma alta demanda de empréstimos e, como já citado, com o pico do tráfego dos estudantes e profissionais do campus. Esta é uma situação comum e bastante inconveniente, tanto para o aluno quanto para o profissional. Outra situação comum é o estresse causado pelo acúmulo de multas por longos períodos de atraso, causado, às vezes, por puro esquecimento do aluno, causando desgaste financeiro e bloqueando o acesso das outras pessoas ao exemplar. Isto é agravado devido ao sistema utilizado atualmente não possuir mecanismos eficientes de lembrete sobre empréstimos atrasados.

A Figura 1 apresenta um esboço do layout da biblioteca. É importante destacar que a biblioteca possui apenas duas portas de acesso situadas ao lado do balcão de empréstimo. Além disso, a biblioteca se encontra no segundo andar do prédio, acessível apenas por elevador ou escada. Nesta figura, indicamos também os locais propostos para a instalação dos leitores antifurto, escolhidos por serem de passagem obrigatória por estudantes que queiram acessar a biblioteca.

A tecnologia RFID se encaixa perfeitamente para resolver os problemas descritos acima. Uma implantação eficiente, onde os leitores e transmissores se comunicam com exatidão, relativos ao espaço no qual eles se encontram, poderá trazer benefícios tanto para os profissionais e alunos, quanto para a Instituição. Contudo, há o fator manutenibilidade com relação a implantação de uma tecnologia como essa. A computação em si, ao longo dos seus anos de aprimoramento e surgimento de tecnologias, nos ensina diariamente que ao resolver grandes problemas, surgem outros (grandes) problemas, por isso, os fatores manutenibilidade e alto acoplamento causados pelo sistema já existente, entram como possíveis obstáculos diários na implantação dessa aplicação. 


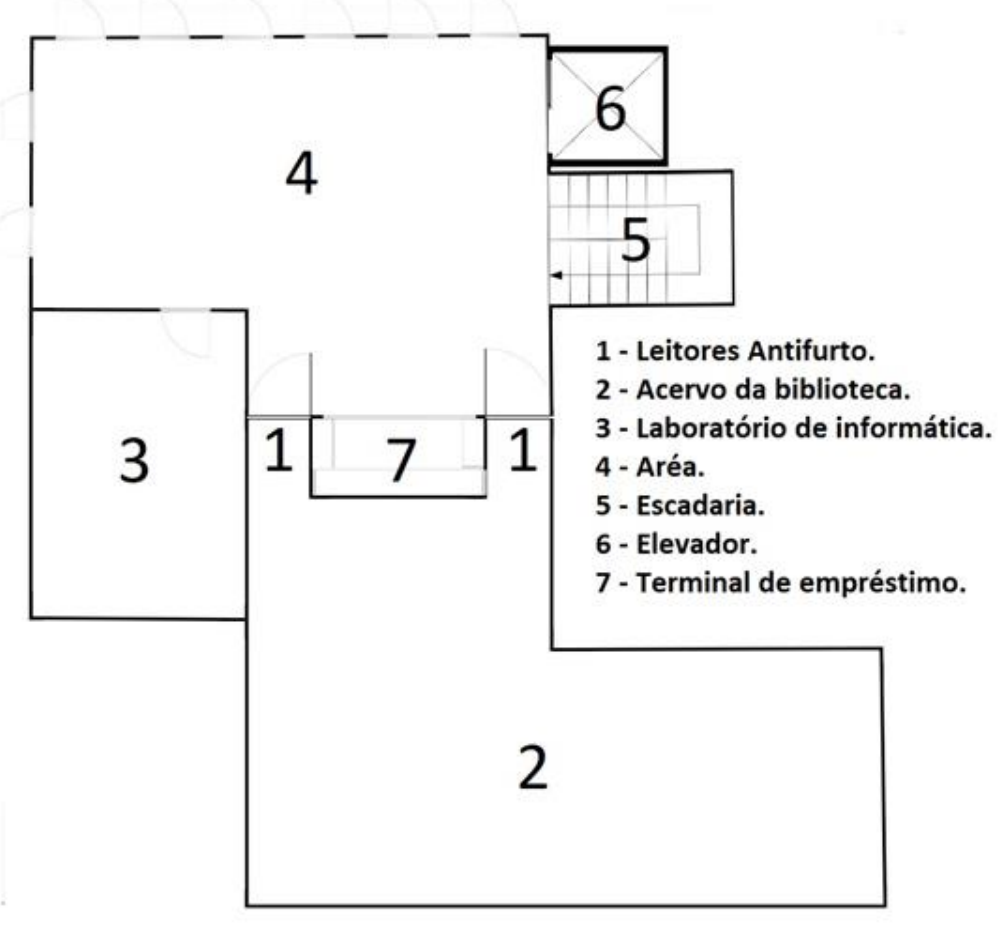

Figura 1. Layout do andar da biblioteca da IESRSA

\section{Resultados}

O padrão que formamos para o bom funcionamento do processo de automatização do fluxo, tem como base a ideia de que cada item do acervo, incluindo TCCs e revistas, tenham uma etiqueta que seja capaz de armazenar seus dados pertinentes. Essa etiqueta carrega consigo um código único, gerado no momento da gravação da mesma, que é capaz de ser comparado ao item do acervo no sistema, além de ter seu bit de sinal que indica o status do item, sendo 0 para emprestado e 1 para livre. Com este recurso, o bibliotecário é capaz de realizar o empréstimo e verificar se uma obra está emprestada apenas transpondo o livro sobre o leitor, eliminando a necessidade de digitar qualquer código. $\mathrm{O}$ leitor fica então encarregado de fazer a leitura, verificação do status do exemplar e consulta ao banco de dados com o código correspondente para finalizar a operação, seja de empréstimo ou devolução.

Para a aplicação do sistema RFID foi necessário o estudo dos mais diversos tipos de transmissores e leitores para que não ocorram erros e interferências nos quais poderiam causar problemas futuros. Para escolher os materiais a serem usados no sistema, levamos em consideração a distância de leitura e escrita do leitor e das etiquetas, bem como a capacidade de armazenamento destas. O leitor deve ter alcance curto, o que exige que o item a ser identificado esteja bastante próximo do leitor. Com isto, evitamos que outros itens próximos sejam detectados por engano. Quanto aos transmissores, eles devem ser do tipo etiqueta, o que permite que eles sejam anexados às obras do acervo com pouca ou nenhuma interferência no armazenamento nas prateleiras da biblioteca. As etiquetas devem também ter capacidade de armazenamento suficiente para identificar todos os itens do acervo, bem como informações adicionais sobre o empréstimo. Uma vez que a biblioteca utilizada neste projeto possui cerca de 40 mil exemplares, estimamos uma capacidade mínima de armazenamento de 17 bits. Destes 16 bits são usados para identificar o exemplar, o que permite a identificação de até 65535 itens. O bit restante indica se o exemplar está emprestado ou não. Além disso, as etiquetas devem ser regraváveis, o que possibilita alterar a situação do empréstimo conforme necessário. 
Em vista disto, foram escolhidos para a realização de testes um leitor MultiTag com frequência de 13,56 Mhz que possibilita a leitura e gravação dos transmissores, e além de transmissores que trabalham na mesma frequência, que são regraváveis para realizar a mudança de status do empréstimo e visualizar a situação do exemplar. Estes transmissores de baixa frequência são boas opções para garantir que não haja interferência de outros equipamentos, como o sistema antifurto disparar mesmo o exemplar tendo sido emprestado ocasionando constrangimento com todos os envolvidos. Para efetivar o sistema antifurto serão comprados 2 leitores com antenas que serão dispostas em cada saída da biblioteca, cada leitor terá o alcance essencial para que seja captado o sinal do transmissores nos exemplares.

\section{Conclusão}

Neste trabalho verificamos a viabilidade de implementação de um sistema utilizando RFID e Arduino em uma biblioteca universitária. Foi constatado que o sistema atual utilizado é bem completo e atende todas as necessidades de uma biblioteca de pequeno porte, se fazendo desnecessário uma total reescrita, por isso, o indicado para uma maior eficiência na aplicação do RFID, no contexto problemático deste projeto, será adaptá-lo ao sistema já existente. Uma técnica conveniente para esse tipo de aplicação é a implementação de um middleware de empréstimos com técnicas de crawler, que é responsável por procurar informações relevantes em uma página web já existente, filtrando o necessário e indexando a um banco de dados local. Assim, poderá ser feita a busca de dados do acervo e atender de modo efetivo a demandas do sistema, e garantir a segurança e confiabilidade da biblioteca, deixando o fluxo de processos não apenas mais rapido, como produtivo, diminuindo equívocos e otimizando todo o processo.

\section{Agradecimentos}

Este trabalho foi financiado pelo Programa Institucional de Bolsas de Iniciação Científica (PIBIC) do Instituto de Educação Superior Raimundo Sá.

\section{Referências}

ROBERTS, C.M. Radio frequency identification (RFID). Computers \& Security, Volume 25, 2006,

FRANÇA NETO, Zamith. Aplicação de tecnologia RFID para gestão acadêmica, de pessoal e operacional de patrimônio e biblioteca. SPOLM, 2008.

SHAHID, Syed Md. Use of RFID Technology in Libraries: a New\# Approach\# to Circulation, Tracking, Inventorying, and Security of Library Materials. Library Philosophy and Practice, 2005.

COYLE, Karen. Managing technology: Management of RFID in Libraries. The Journal of Academic Librarianship, 2005. 